\title{
Cerebral Angiography for Evaluation of Patients with CT Angiogram-Negative Subarachnoid Hemorrhage: An 11-Year Experience
}

\author{
(D).J. Heit, (D) G.T. Pastena, DR.G. Nogueira, (D)A.J. Yoo, (D)T.M. Leslie-Mazwi, (D).A. Hirsch, and (D).D. Rabinov
}

\begin{abstract}
BACKGROUND AND PURPOSE: CT angiography is increasingly used to evaluate patients with nontraumatic subarachnoid hemorrhage given its high sensitivity for aneurysms. We investigated the yield of digital subtraction angiography among patients with SAH or intraventricular hemorrhage and a negative CTA.
\end{abstract}

MATERIALS AND METHODS: An 11-year, single-center retrospective review of all consecutive patients with CTA-negative SAH was performed. Noncontrast head CT, CTA, DSA, and MR imaging studies were reviewed by 2 experienced interventional neuroradiologists and 1 neuroradiologist.

RESULTS: Two hundred thirty patients (mean age, 54 years; $51 \%$ male) with CTA-negative SAH were identified. The pattern of SAH was diffuse $(40 \%)$, perimesencephalic (31\%), sulcal $(31 \%)$, isolated IVH $(6 \%)$, or identified by xanthochromia $(7 \%)$. Initial DSA yield was $13 \%$, including vasculitis/vasculopathy (7\%), aneurysm (5\%), arteriovenous malformation ( $0.5 \%)$, and dural arteriovenous fistula (0.5\%). An additional 6 aneurysms/pseudoaneurysms (4\%) were identified by follow-up DSA, and a single cavernous malformation (0.4\%) was identified by MRI. No cause of hemorrhage was identified in any patient presenting with isolated intraventricular hemorrhage or xanthochromia. Diffuse SAH was due to aneurysm rupture (17\%); perimesencephalic SAH was due to aneurysm rupture (3\%) or vasculitis/vasculopathy (1.5\%); and sulcal SAH was due to vasculitis/vasculopathy (32\%), arteriovenous malformation (3\%), or dural arteriovenous fistula (3\%).

CONCLUSIONS: DSA identifies vascular pathology in $13 \%$ of patients with CTA-negative SAH. Aneurysms or pseudoaneurysms are identified in an additional $4 \%$ of patients by repeat DSA following an initially negative DSA. All patients with CT-negative SAH should be considered for DSA. The pattern of SAH may suggest the cause of hemorrhage, and aneurysms should specifically be sought with diffuse or perimesencephalic SAH.

ABBREVIATION: IVH = intraventricular hemorrhage

N

ontraumatic subarachnoid hemorrhage occurs in 30,000 patients per year in the United States, which accounts for $5 \%$ of strokes. ${ }^{1}$ Patient mortality approximates $45 \%$ within a month after $\mathrm{SAH},{ }^{1}$ and the identification of a treatable cause of $\mathrm{SAH}$ is imperative.

Cerebral aneurysm rupture accounts for most SAHs, ${ }^{2}$ but a

Received May 12, 2015; accepted after revision June 22.

From the Department of Radiology (J.J.H.), Interventional Neuroradiology Division, Stanford University Hospital, Stanford, California; Department of Radiology (G.T.P.), Albany Medical Center, Albany, New York; Departments of Neurology, Neurosurgery, and Radiology (R.G.N.), Emory University School of Medicine, Marcus Stroke and Neuroscience Center, Atlanta, Georgia; Department of Neuroradiology and Interventional Neuroradiology (T.M.L.-M., J.A.H., J.D.R.), Massachusetts General Hospital, Boston, Massachusetts; and Texas Stroke Institute (A.J.Y.), Plano, Texas.

Please address correspondence to James D. Rabinov, MD, Interventional Neuroradiology, Gray 241, Massachusetts General Hospital, 55 Fruit St, Boston, MA 02114;

e-mail: jrabinov@partners.org

http://dx.doi.org/10.3174/ajnr.A4503 cause of hemorrhage is not identified in $15 \%-20 \%$ of patients. ${ }^{2-4}$ Prior studies have demonstrated that the pattern of SAH on a noncontrast head CT may predict the probability of identifying a causative vascular lesion, though CT angiography or digital subtraction angiography is needed to identify these lesions. ${ }^{5-9}$

The evaluation of SAH varies, and no consensus exists as to the best algorithm. Increasingly, CTA is performed in the evaluation of $\mathrm{SAH}$, given its noninvasive nature and wide availability. CTA has a reported a sensitivity of $97 \%-100 \%$ for the detection of intracranial aneurysms. ${ }^{10-13}$ However, it fails to identify a cause for SAH in 5\%$30 \%$ of patients. ${ }^{14,15}$ DSA remains the criterion standard in the diagnosis of vascular lesions resulting in SAH with a reported sensitivity of $99 \% .^{16,17}$ Given the superior sensitivity of DSA and the importance of identifying a treatable cause of SAH, DSA is frequently performed in patients presenting with $\mathrm{SAH}$ and negative CTA findings.

Prior studies demonstrated that DSA identifies a cause of SAH 
Table 1: Demographic data of patients presenting with subarachnoid or isolated intraventricular hemorrhage without a causative lesion on CTA

\begin{tabular}{lccc}
\hline & Total & Men & Women \\
\hline No. of Patients & 230 & 118 & 112 \\
Mean age $(y r)$ & 54 & 55 & 54 \\
Age range & $19-92$ & $21-92$ & $19-87$ \\
SAH found by CT & 216 & 106 & 110 \\
SAH found by lumbar puncture & 14 & 7 & 7 \\
Mean time between CTA and DSA (days) & 1.5 & 1.0 & 2.0 \\
Time range between CTA and DSA (days) & $0-110$ & $0-5$ & $0-110$ \\
Second follow-up study performed (No. of patients) & 169 & 86 & 83 \\
Mean time between initial and follow-up study (days) & 33 & 24 & 42 \\
Time range between initial and follow-up study (days) & $0-1836$ & $0-203$ & $0-1836$ \\
Second follow-up modality & & & 26 \\
$\quad$ CTA & 54 & 28 & 26 \\
DSA & 98 & 45 & 7 \\
MRI/MRA & 17 & 10 & 53 \\
\hline
\end{tabular}

1.25-mm collimation, 350 maximal $\mathrm{mA}$, $120 \mathrm{kVP}$, and 22-cm FOV. We administered $65-85 \mathrm{~mL}$ of iodinated contrast by power injector at $4-5 \mathrm{~mL} / \mathrm{s}$ into an antecubital vein, and image acquisition was initiated with either a fixed 25-second delay after injection, SmartPrep software (GE Healthcare), or semiautomatic contrast bolus triggering. Axial, coronal, and sagittal maximum-intensityprojection images were available at the time of study review and curvilinear 3D reformations were created by an independent processing laboratory.

MR imaging and MRA were performed on either $1.5 \mathrm{~T}$ or $3 \mathrm{~T}$ scanners (Signa 1.5T; GE Healthcare; or Tim Trio in $4 \%-14 \%$ of patients with negative CTA findings. ${ }^{3,4,14,18-20}$ Moreover, the diagnostic yield of repeat DSA after initially negative DSA findings is reported to be between $4 \%$ and $16 \%{ }^{14,15,21}$ We describe our experience with initial and repeat DSA in patients with CTA negative for SAH during an 11-year period at a large neurovascular referral center.

\section{MATERIALS AND METHODS \\ Patient Selection}

We retrospectively reviewed the radiology data base and medical records of all patients who presented to our hospital (Massachusetts General Hospital) during an 11-year period (January 1, 2002, through December 31, 2012) with the following: 1) nontraumatic subarachnoid hemorrhage or isolated intraventricular hemorrhage identified by noncontrast head CT or xanthochromia on lumbar puncture, 2) initial evaluation with a CTA that failed to identify a cause of SAH, and 3) at least 1 cerebral DSA. If an initial cerebral DSA was negative for SAH, patients underwent additional studies.

Follow-up DSA was planned in all patients at an interval of 7-10 days unless there was a contraindication such as arterial dissection or death, and some patients underwent DSA in a shorter time interval due to a clinical deterioration or other evidence of cerebral arterial vasospasm. If a diagnosis was made by a noninvasive imaging study, including CTA or MR imaging/MRA, a follow-up DSA was not performed. Noninvasive imaging studies were performed at the discretion of the physician caring for the patient.

Incidental aneurysms identified by DSA were not considered causative of SAH and comprised additional aneurysms distinct from the ruptured lesions or aneurysms remote from the region of SAH. The study was approved by the institutional review board of our hospital and complied with the Health Insurance Portability and Accountability Act.

\section{Image Acquisition and Analysis}

NCCT was performed with standard protocols by using a 16- or 64-section helical CT scanner (LightSpeed; GE Healthcare, Milwaukee, Wisconsin). Axial NCCT images were obtained with 120-140 kV(peak), $170 \mathrm{~mA}$, and 5-mm-section-thickness reconstruction. CTA was performed by axial acquisition from the base of the $\mathrm{C} 1$ vertebral body to the vertex by using an 0.5 pitch,
3T; Siemens, Erlangen, Germany) by using standard departmental and vendor protocols.

DSA was performed in a biplane neuroangiography suite (Axiom Artis; Siemens) following transfemoral arterial access under intravenous conscious sedation or general anesthesia. Biplanar DSA images were obtained after selective catheterization of the bilateral common carotid arteries and at least 1 vertebral artery and injection with iodinated contrast. Additional selective injection of the internal, external, or contralateral vertebral artery was performed at the discretion of the neurointerventionalist. 3D rotational angiography was performed at the discretion of the interventional neuroradiologist. Standard views typically included frontal, lateral, and oblique views of each selected vessel.

All NCCT, CTA, and DSA images were independently reviewed by 2 interventional neuroradiologists and 1 neuroradiologist to determine the presence and pattern of $\mathrm{SAH}$, including the following: 1) absence of SAH, or 2) perimesencephalic, 3) sulcal, and 4) diffuse SAH. Perimesencephalic SAH was considered largely within the interpeduncular, prepontine, ambient, quadrigeminal plate or premedullary cistern with minimal extension into the medial Sylvian fissures. This imaging review was performed near the end of the 11-year study period when the manuscript was being prepared. The presence of intraventricular hemorrhage (IVH) was also identified. CTA images were reviewed for a vascular cause of SAH. If vessel irregularity was identified, DSA was performed to determine whether the irregularity represented vasospasm in the region of SAH versus a vasculitis or vasculopathy and for the presence of an aneurysm. If an aneurysm was identified by DSA after a CTA negative for SAH, the CTA was reviewed retrospectively. These studies were included as falsenegative ones.

\section{Medical Record Review}

Patient demographic information and clinical outcome were reviewed in the electronic Longitudinal Medial Record system available at our hospital.

\section{Statistical Analysis}

Statistical analysis was performed by using Excel (Microsoft, Redmond, Washington) and XLSTAT (Addinsoft, New York, New York). A $P$ value of .05 was statistically significant. 

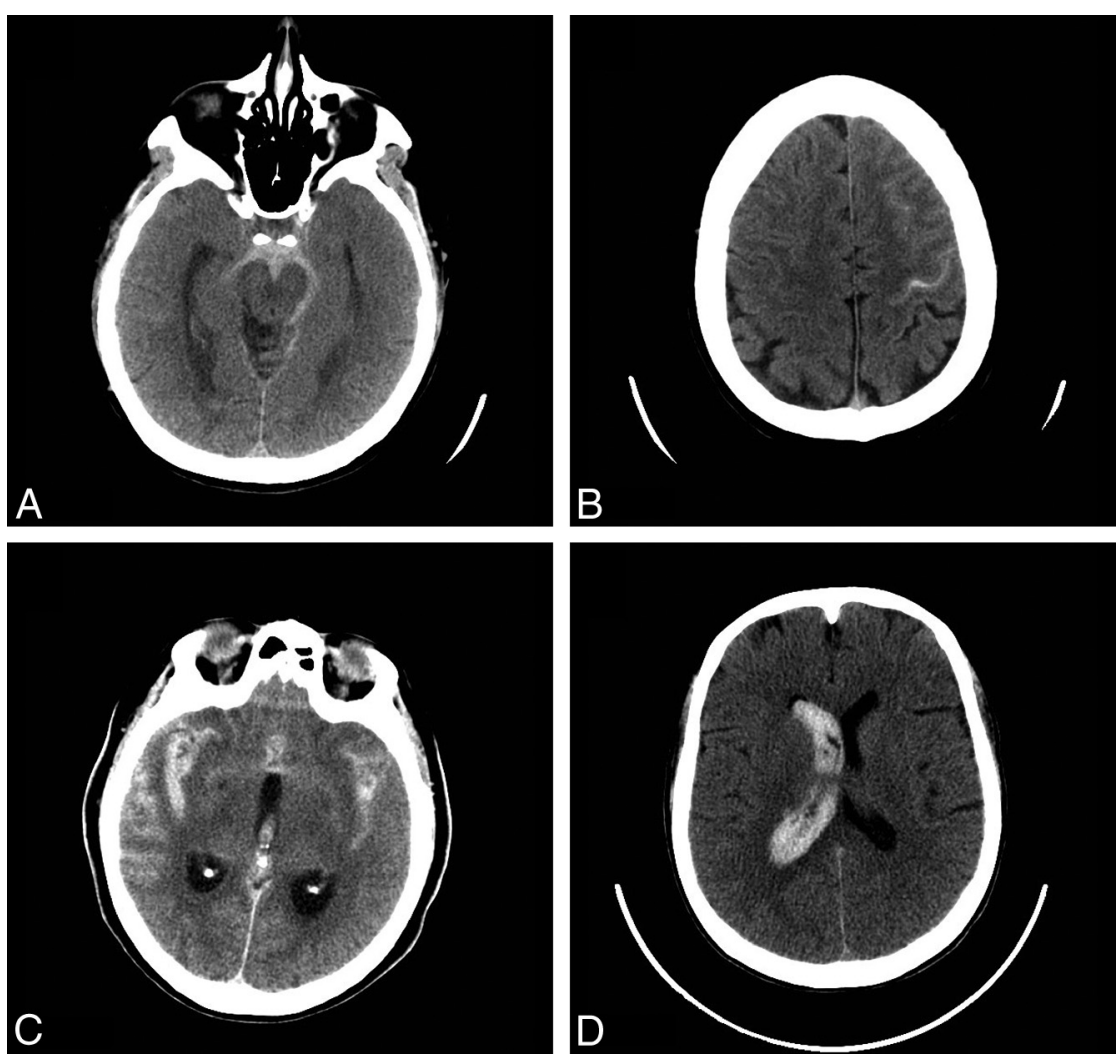

FIG 1. Noncontrast head CT examples of SAH. Perimesencephalic SAH: axial image from a noncontrast head CT demonstrates acute SAH in the prepontine and interpeduncular cistern, consistent with a perimesencephalic pattern of SAH $(A)$. Sulcal SAH: axial image from a noncontrast head CT demonstrates acute SAH in the left precentral sulcus and in the sulci overlying the left middle frontal gyrus, consistent with a sulcal pattern of SAH (B). Diffuse SAH: axial image from a noncontrast head CT demonstrates acute SAH in the bilateral Sylvian fissures, overlying the sulci of the bilateral temporal lobes, consistent with a diffuse pattern of SAH. Note also intraventricular hemorrhage within the third ventricle $(C)$. Isolated IVH: axial image from a noncontrast head CT demonstrates acute intraventricular hemorrhage casting the right lateral ventricle $(D)$.

Table 2: Pattern of subarachnoid hemorrhage and the presence of intraventricular hemorrhage

\begin{tabular}{lccc}
\hline & All & Men & Women \\
\hline Pattern of SAH & & & \\
None & $29(13 \%)$ & $15(14 \%)$ & $14(12 \%)$ \\
Perimesencephalic & $71(31 \%)$ & $38(34 \%)$ & $33(28 \%)$ \\
Sulcal & $37(16 \%)$ & $15(14 \%)^{2}$ & $22(18 \%)$ \\
Diffuse & $93(40 \%)$ & $43(39 \%)$ & $50(42 \%)$ \\
Xanthochromia on lumbar puncture & $16(7 \%)$ & $8(7 \%)$ & $8(7 \%)$ \\
Isolated intraventricular hemorrhage & $13(6 \%)$ & $7(6 \%)$ & $6(5 \%)$ \\
\hline
\end{tabular}

${ }^{a} P=.0001$ by Fisher exact test.

\section{RESULTS}

From January 1, 2002, to December 31, 2012, 1288 patients presented with nontraumatic SAH. CTA identified an aneurysm as the cause of SAH in 1058 patients (82\%), and the CTAs typically provided sufficient data for treatment triage by microsurgical clipping or endovascular coil embolization. The 1058 patients with aneurysms identified by CTA were excluded from the analysis. The remaining 230 patients had SAH or isolated IVH and a CTA that failed to reveal a causative lesion. These 230 patients (17.9\% of patients with SAH) included 118 men (51\%) and 112 women $(49 \%)$, and the average patient age was 54 years (Table 1 ).

SAH was identified by CT in 216 patients (94\%) and by CSF xanthochromia on lumbar puncture in 14 patients $(6 \%)$. In patients with SAH identified by CT, the SAH distribution was perimesencephalic in 71 patients (31\%), sulcal in 37 patients (16\%), and diffuse in 93 patients (40\%). Representative imaging examples of each type of SAH are show in Fig 1. Sulcal SAH was identified in 22 women and 15 men ( $18 \%$ and $14 \%$, respectively; $P<.001$ ), and there was no significant difference in the prevalence of other distributions of SAH between men and women (Table 2). Isolated IVH was identified in 13 patients $(6 \%)$ by CT (Table 2).

All 230 patients underwent an initial cerebral DSA within a mean of 1.5 days (median, 1 day; range, $0-14$ days; and a single outlier performed at 110 days). These studies identified a causative lesion for SAH in 29 patients (13\%), including 12 aneurysms (5\%), 15 cases of vasculitis or vasculopathy (7\%), 1 arteriovenous malformation $(0.05 \%)$, and 1 dural arteriovenous fistula (0.05\%). Vasculitis or vasculopathy (Fig 2) was identified in 11 female patients and 4 men $(73 \%$ and $27 \%$, respectively; $P=$ $.03)$, and there was no significant difference in the prevalence of other causative lesions between men and women (Table 3).

No causative lesion for $\mathrm{SAH}$ was identified by initial DSA, CTA, or MR imaging in patients with xanthochromia on lumbar puncture and no CT evidence of SAH (16 patients, Table 4). Similarly, no causative lesion for SAH was identified by DSA, CTA, or MR imaging in patients with isolated IVH (13 patients, Table 4).

In patients with perimesencephalic SAH (71 patients), 2 aneurysms $(3 \%)$ and 1 case of vasculitis/vasculopathy (1.5\%) were identified (Table 4). However, no source of the hemorrhage was identified in 68 of these patients $(96 \%)$. By contrast, in patients presenting with sulcal SAH (37 patients), 12 cases of vasculitis/ vasculopathy (30\%), 1 AVM (3\%), and 1 dural AVF (3\%) were identified. No aneurysms were identified that resulted in a sulcal pattern of SAH. In patients with diffuse SAH (93 patients), 16 aneurysms (17\%) and no other vascular lesions were identified.

Additional studies were performed in 169 patients who had an initial CTA negative for SAH and DSA, including repeat DSA (98 patients), repeat CTA (54 patients), MR imaging/MRA (17 patients), or a combination of these modalities. These follow-up studies were performed within a mean of 33 days (median, 8 days; range, 0-252 days with an outlier at 1836 days; Table 1 ). A causative lesion for $\mathrm{SAH}$ was identified through these follow-up studies in an additional 7 patients (4\%). Six de novo aneurysms/pseudoaneurysms were identified by CTA (and subsequently also by DSA, Figs 3 and 4), and all 6 

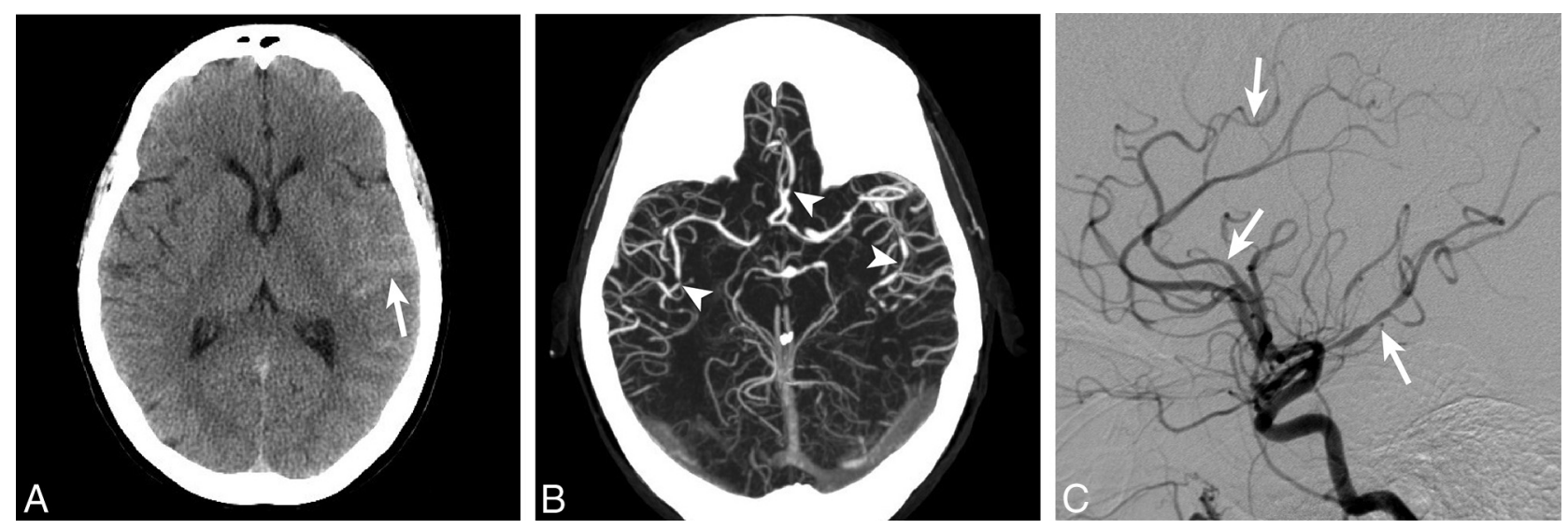

FIG 2. Cerebral arterial vasculitis identified on DSA. A 45-year-old woman who presented with sulcal SAH (arrow) isolated to the left Sylvian fissure (A). A CTA at the time of admission demonstrated multifocal arterial narrowing (arrowheads) within the bilateral anterior and middle cerebral arteries $(B)$. DSA identified more extensive bilateral arterial irregularity with multifocal narrowing and dilation that was consistent with vasculitis.

Table 3: Diagnosis as determined by digital subtraction angiography

\begin{tabular}{lccc}
\hline & All & Men & Women \\
\hline Diagnosis after initial DSA & & & \\
$\quad$ No causative lesion & $201(87 \%)$ & $110(55 \%)^{\mathrm{a}}$ & $91(45 \%)$ \\
Aneurysm & $12(5 \%)$ & $3(25 \%)$ & $9(75 \%)$ \\
Arteriovenous & $2(1 \%)$ & $1(50 \%)$ & $1(50 \%)$ \\
$\quad$ malformation & & & \\
Arteriovenous fistula & $1(0.5 \%)$ & $1(100 \%)$ & $0(0 \%)$ \\
Vasculitis/vasculopathy & $15(7 \%)$ & $3(21)^{\mathrm{b}}$ & $11(79 \%)$ \\
\hline
\end{tabular}

a $P=.01$ by Fisher exact test.

$\mathrm{b} P=.03$ by Fisher exact test.

patients initially presented with a diffuse pattern of SAH. One cavernous malformation was identified by MR imaging in a patient who presented with xanthochromia (Table 5).

The neurologic complication rate from diagnostic cerebral angiography was $<0.5 \%$ in all patients.

\section{DISCUSSION}

The use of CTA as a primary imaging and triage technique in patients presenting with SAH results in decreased time to diagnosis and reduced medical costs. ${ }^{22}$ At our large neurovascular referral center, all patients presenting with SAH undergo a CTA of the head, and this technique identified an aneurysm as the cause of $\mathrm{SAH}$ in $82 \%$ of patients during an 11-year period. For much of this period, the bulk of patients who underwent subsequent craniotomy for ruptured aneurysms did not undergo preoperative DSA examination.

We investigated the yield of DSA in the remaining 230 patients with SAH and a negative initial evaluation by CTA (17.9\% of all patients presenting with nontraumatic SAH). Initial DSA determined the cause of SAH in 13\% of these patients, corresponding to a $13 \%$ false-negative rate of CTA, which is similar to that in prior studies. ${ }^{7,23,24}$ By contrast, other studies have found a lower yield of $4 \%-7 \%$ of DSA in patients with $\mathrm{SAH}$ and a negative initial evaluation by CTA, ${ }^{5,6,25}$ possibly reflecting differences in patient populations. 3D rotational angiography was not routinely performed, and the benefit of this technique in the evaluation of SAH remains controversial. ${ }^{26,27}$ These data further underscore the importance of pursuing DSA in patients with CTA negative for SAH to identify a treatable vascular pathology.

\section{Vascular Lesions Resulting in SAH}

The most common identified cause of SAH in our series was vasculitis or vasculopathy, including Call-Flemming or reversible cerebral vasoconstriction syndrome, which accounted for $7 \%$ of the abnormalities identified on the initial DSA (Fig 2). Vascular narrowing and irregularity on DSA may also be seen in patients with vasospasm following SAH. However, vasospasm typically occurs 3-5 days after initial intracranial hemorrhage, is most commonly observed after rupture of an intracranial aneurysm, and is most strongly correlated with a diffuse pattern of $\mathrm{SAH} .{ }^{28}$ By contrast, the vascular narrowing and irregularity identified in our series was identified by DSA performed within the first 2 days of presentation with SAH. Moreover, the pattern of SAH in patients with vasculitis or vasculopathy was sulcal (11 patients) or perimesencephalic (1 patient), and these patterns are less commonly associated with vasospasm than diffuse patterns of hemorrhage. These differences strongly suggest that the vascular narrowing and irregularity in these patients are most consistent with a primary vascular pathology rather than vasospasm.

The second most frequent cause of SAH in our series was rupture of an intracranial aneurysm (12 patients; 5\%). Repeat DSA identified an additional 6 patients with de novo aneurysms or pseudoaneurysms. Thus, aneurysms were identified in 18 patients, which accounts for an $8 \%$ yield of DSA for this pathology. Types of aneurysms that may potentially be missed by initial CTA include small bifurcation aneurysms or those on a curve of a vessel, dissecting aneurysms (Fig 3), perforator aneurysms (Fig 4), and small infectious or myxomatous aneurysms. This yield of initial DSA is slightly higher than that in prior studies, which identified aneurysms in approximately $2 \%$ of patients with CTA negative for SAH. ${ }^{5,7}$ This discrepancy in the yield of DSA for the detection of aneurysms may reflect differences in the patient populations, the size of patient cohorts, or even differences in the sensitivity of CTA for aneurysms among different centers.

Vascular lesions resulting in abnormal arteriovenous shunting, including AVMs and dural AVFs, were uncommonly identified by DSA in our series. Only 1 AVM and 1 dural AVF were identified, both of which presented with a sulcal pattern of SAH. The relative rarity of AVMs and AVFs in our series may reflect the 
Table 4: Subarachnoid hemorrhage pattern and final diagnosis ${ }^{a}$

\begin{tabular}{lccccc}
\hline & \multicolumn{5}{c}{ Pattern of SAH } \\
\cline { 2 - 6 } & No SAH & Perimesencephalic & Sulcal & Diffuse & IVH \\
\hline No source identified & 0 & $68(96 \%)$ & $24(65 \%)$ & $79(85 \%)$ & $13(100 \%)$ \\
Aneurysm/pseudoaneurysm & 0 & $2(3 \%)$ & 0 & $16(17 \%)$ & 0 \\
AVF & 0 & 0 & $1(3 \%)$ & 0 & 0 \\
AVM & 0 & 0 & $1(3 \%)$ & 0 & 0 \\
Vasculitis & 0 & $1(1.5 \%)$ & $12(32 \%)$ & 0 & 0 \\
Cavernous malformation & $1(3 \%)$ & 0 & 0 & 0 & 0 \\
\hline
\end{tabular}

a Percentages reflect patient percentage with a vascular pathology within each SAH pattern.

b "No SAH" refers to patients with xanthochromia or isolated IVH.
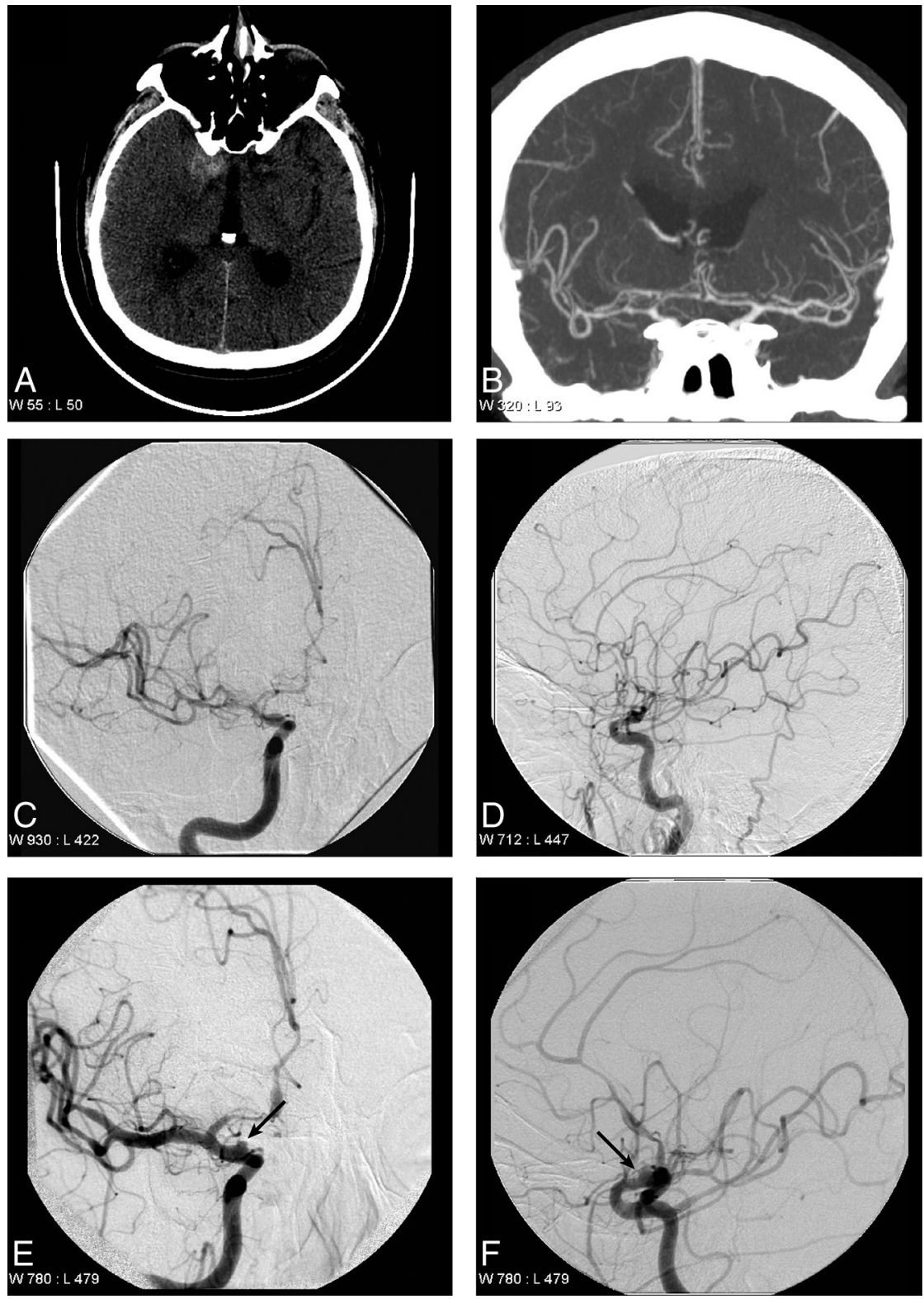

FIG 3. Supraclinoid internal carotid artery aneurysm identified on repeat DSA. A 72-year-old man who presented with perimesencephalic $S A H$ that is localized near the right clinoid process $(A)$. An initial CTA performed on the day of presentation did not identify a lesion responsible for the SAH (B). DSA performed on the day after presentation demonstrates relative narrowing of the right supraclinoid internal carotid artery, the right middle cerebral artery, and the right anterior cerebral artery in the anteroposterior $(C)$ and lateral $(D)$ projections, which was thought to represent early vaspospasm. A follow-up DSA was performed 7 days after presentation, which demonstrates an irregular saccular outpouching (arrows) arising from the supraclinoid internal carotid artery in the anteroposterior $(E)$ and lateral $(F)$ projections, consistent with a dissecting aneurysm. high sensitivity of CTA for the detection of these lesions, which would lead to their exclusion in our study. Moreover, patients with ruptured AVMs frequently present with intraparenchymal hemorrhage and SAH. At our institution, patients with intraparenchymal hemorrhage most often undergo MR imaging to exclude the presence of an underlying mass lesion. Our MR imaging protocols include advanced sequences such as arterial spin-labeling and susceptibilityweighted imaging, which have been shown to be very sensitive for arteriovenous shunting. ${ }^{29,30}$ Based on this diagnostic algorithm, a presumptive diagnosis of an AVM or dural AVF is typically made by CTA and MR imaging at our institution, which likely accounts for the relative paucity of these lesions in this series.

\section{Patterns of SAH and Cause of Hemorrhage}

In our series, the distribution of SAH was diffuse $(40 \%)$, perimesencephalic (31\%), sulcal (16\%), or identified by lumbar puncture (13\%), which is similar to the distribution identified in prior studies. ${ }^{5,7,20}$ Similar to authors in prior studies, ${ }^{2,13}$ we found the distribution of SAH to be highly correlated with specific vascular lesions, as described in detail below.

The yield of DSA in patients with diffuse $\mathrm{SAH}$ was $17 \%$, which is similar to the $10 \%-15 \%$ in prior studies. ${ }^{5,7}$ Aneurysms were the only pathology identified that resulted in diffuse $\mathrm{SAH}$, and most of these aneurysms (12 patients; 13\%) were identified on initial DSA. However, 6 additional de novo aneurysms/pseudoaneurysms were identified on repeat DSA in patients with diffuse SAH (see below). Therefore, we recommend careful inspection for the presence of aneurysms in patients presenting with diffuse SAH.

By contrast, the yield of DSA in patients presenting with perimesencephalic hemorrhage was $4.5 \%$, which is similar to the $0 \%-5 \%$ yield in prior studies. $^{5,7-9}$ Perimesencephalic SAH typically correlates with a more benign clinical course compared with other patterns of SAH and is the least likely pattern to result in a positive finding on DSA. $^{2,31}$ Several studies have argued that no further investigation is necessary 

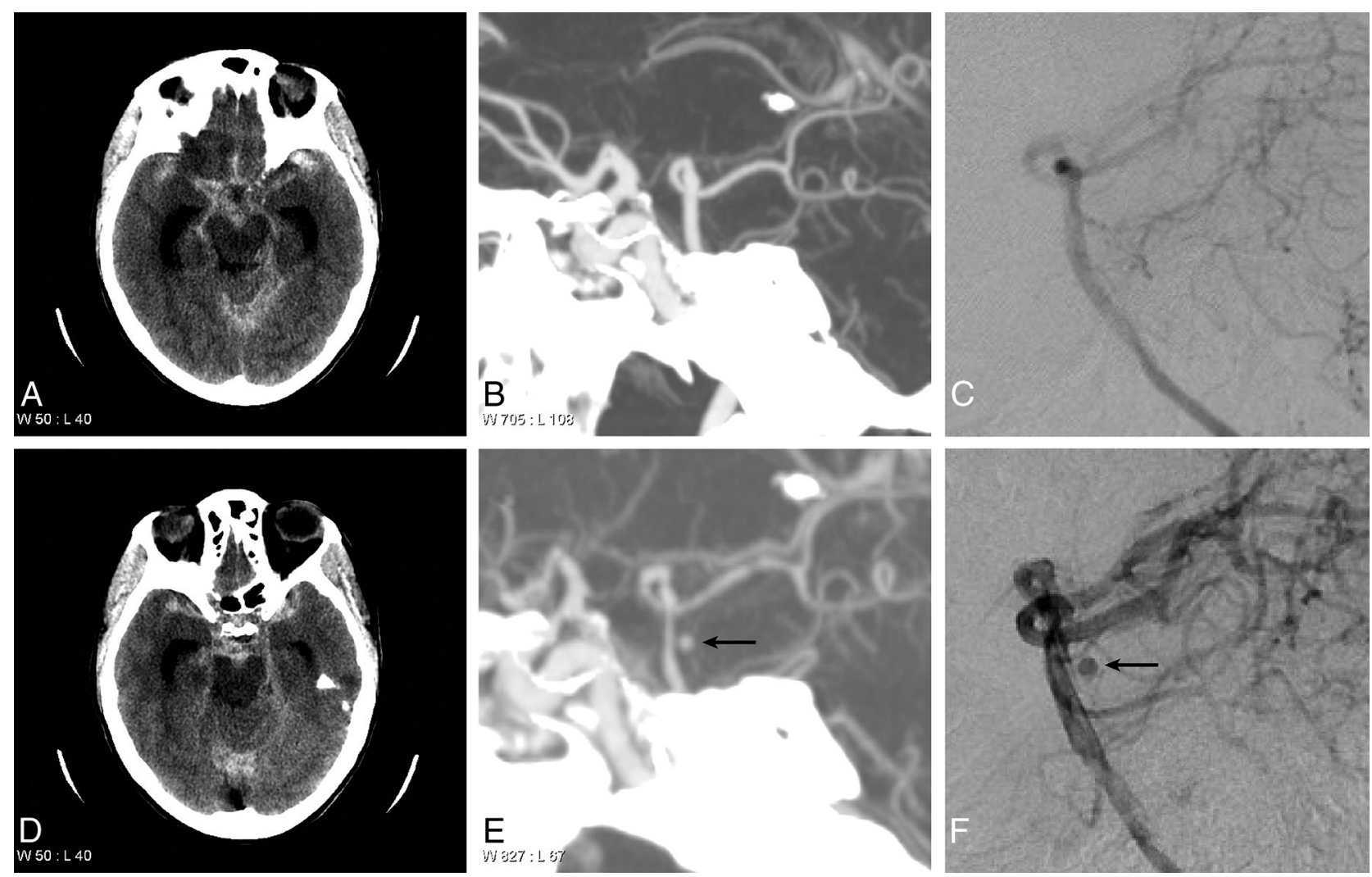

FIG 4. Basilar artery aneurysm identified on repeat CTA and DSA. A 65-year-old woman who presented with diffuse SAH in the basal cisterns and bilateral Sylvian fissures. Note hydrocephalus $(A$ and $D)$. A maximum-intensity-projection image from a CTA $(B)$ and a DSA $(C)$ performed on the day of presentation demonstrate no evidence of an aneurysm arising from the basilar artery. A follow-up CTA (E) and DSA (F) performed 7 days after presentation demonstrate an aneurysm arising from the posterior aspect of the basilar artery, consistent with a perforator artery aneurysm.

Table 5: Additional diagnosis identified on follow-up CTA, DSA, or MRI

\begin{tabular}{lccc} 
or MRI & All & Men & Women \\
\hline $\begin{array}{l}\text { Total No. of patients undergoing } \\
\quad \text { follow-up studies }\end{array}$ & 169 & 86 & 83 \\
$\begin{array}{l}\text { Additional diagnosis after follow-up } \\
\quad \text { studies: }\end{array}$ & & & \\
$\quad \begin{array}{llll}\text { Aneurysm/pseudoaneurysm } \\
\quad \text { Cavernous malformation }\end{array}$ & $6(4 \%)$ & $3(3 \%)$ & $3(4 \%)$ \\
& $1(0.6 \%)$ & $0(0 \%)$ & $1(1 \%)$ \\
\hline
\end{tabular}

in patients with CTA negative for SAH based on a negative yield of DSA in their series. ${ }^{5,9}$ By contrast, we and others ${ }^{23}$ have found that though the yield of DSA was low in these patients, an aneurysm was responsible for perimesencephalic SAH in 3\% of patients. We also found a single case of vasculitis accounting for perimesencephalic SAH, which resulted in an active change to the clinical management of this patient. On the basis of these data and the low risk of DSA, we recommend that all patients presenting with CTA negative for perimesencephalic SAH continue to undergo DSA.

A sulcal pattern of SAH resulted in the highest yield of DSA, with a finding rate of $38 \%$. Similar to a prior study, ${ }^{6}$ nearly onethird (32\%) of patients with sulcal SAH were found to have vasculitis or vasculopathy. We found a single AVM and a single dural AVF that resulted in a sulcal pattern of SAH. No aneurysms resulted in sulcal SAH. All of these vascular pathologies were identified on the initial DSA, suggesting that follow-up DSA is not required for diagnostic purposes in patients presenting with sulcal SAH. Most interesting, sulcal SAH was significantly more likely to be found in women. Although the reported incidence of central nervous system vasculitis is equal among men and women, ${ }^{32}$ other cerebral vasculopathies, including reversible cerebral vasoconstriction syndrome, are more common in women, which may account for this difference in our series. ${ }^{33}$

The yield of DSA in patients with either xanthochromia or isolated IVH was zero in our series. However, prior studies have found aneurysms as a cause of xanthochromia in approximately $8 \%$ of patients. ${ }^{34}$ Similarly, prior studies have found a high yield of DSA in patients with isolated IVH, though the sensitivity of CTA in the setting of isolated IVH has been poorly described. ${ }^{35}$ Therefore, at least 1 DSA is prudent in these patients.

\section{Follow-Up Diagnostic Studies}

At our institution, patients with CTA negative for SAH and negative findings on initial DSA undergo further imaging evaluation. We found an additional 6 aneurysms/pseudoaneurysms in 169 patients on repeat DSA performed 1 week after the initial DSA (4\% detection rate). Similarly, prior studies have found a repeat DSA yield of $4 \%-16 \%$ in patients presenting with SAH and an initial CTA and DSA negative for SAH. ${ }^{7,20,23,24,36}$ Nondetection of a ruptured aneurysm on initial DSA may be due to vasospasm of the parent vessel, compression of the aneurysm by an adjacent hematoma, development of a de novo aneurysm/pseudoaneu- 
rysm, or a small size of the aneurysm in combination with these factors. ${ }^{37}$ Most interesting, the 6 aneurysms found on repeat DSA were also prospectively identified by repeat CTA that was performed for vasospasm triage purposes before the repeat DSA. It would be of interest to determine the sensitivity of CTA in the delayed detection of a ruptured aneurysm among a greater number of patients.

An MR imaging performed after a negative initial DSA identified a cortical cavernous malformation as a cause of SAH in a single patient. This patient initially presented with an acute headache and NCCT that was negative for intracranial hemorrhage. Xanthochromia was identified by lumbar puncture, which eventually led to the diagnosis. Cavernous malformations have previously been identified as a cause of perimesencephalic $\mathrm{SAH},{ }^{38}$ though SAH is an uncommon presentation of these lesions.

\section{Limitations}

The limitations of this study include a selection bias due to the study occurring at a large tertiary care and neurovascular referral center and the retrospective nature of the study. This selection bias may limit the generalizability of our findings.

\section{CONCLUSIONS}

Careful evaluation of patients presenting with CTA negative for SAH should include DSA, even in case of perimesencephalic SAH, given the significant $13 \%$ yield of DSA in identifying a vascular pathology that resulted in the hemorrhage. Furthermore, continued investigation is prudent by CTA, DSA, and/or MR imaging in patients with an initial DSA negative for SAH after a CTA negative for $\mathrm{SAH}$, given a $4 \%$ yield of these follow-up studies.

Disclosures: Raul G. Nogueira—UNRELATED: Consultancy: Covidien (Study of Tamoxifen and Raloxifene Trial core lab); OTHER RELATIONSHIPS: Stryker/Concentric Medical: Trevo 2 Trial Principal Investigator, DWI/PWI and CTP Assessment in the Triage of Wake-Up and Late Presenting Strokes Undergoing Neurointervention Trial Principal Investigator (unpaid); Covidien/ev3: Solitaire Flow Restoration Device versus the Merci Retriever in Patients with Acute Ischaemic Stroke; and Solitaire With the Intention For Thrombectomy as PRIMary Endovascular Treatment Trials Steering Committee (unpaid); Covidien: 3D Separator Trial Executive Committee (unpaid). Joshua A. Hirsch—UNRELATED: Consultancy: Medtronic, CareFusion, Comments: Medtronic, ongoing consultancy concerning interventional spine; CareFusion, taught a non-Continuing Medical Education course; Stock/Stock Options: Intratech, Brainstorm.

\section{REFERENCES}

1. Bederson JB, Connolly ES Jr, Batjer HH, et al; American Heart Association. Guidelines for the management of aneurysmal subarachnoid hemorrhage: a statement for healthcare professionals from a special writing group of the Stroke Council, American Heart Association. Stroke 2009;40:994-1025 CrossRef Medline

2. Rinkel GJ, Wijdicks EF, Hasan D, et al. Outcome in patients with subarachnoid haemorrhage and negative angiography according to pattern of haemorrhage on computed tomography. Lancet 1991; 338:964-68 CrossRef Medline

3. Duong HH, Melançon DD, Tampieri DD, et al. The negative angiogram in subarachnoid haemorrhage. Neuroradiology 1996;38:15-19 CrossRef Medline

4. Kaim A, Proske M, Kirsch E, et al. Value of repeat-angiography in cases of unexplained subarachnoid hemorrhage (SAH). Acta Neurol Scand 1996;93:366-73 Medline

5. Agid R, Andersson T, Almqvist H, et al. Negative CT angiography findings in patients with spontaneous subarachnoid hemorrhage: when is digital subtraction angiography still needed? AJNR Am J Neuroradiol 2010;31:696-705 CrossRef Medline

6. Agid R, Lee SK, Willinsky RA, et al. Acute subarachnoid hemorrhage: using 64-slice multidetector CT angiography to "triage” patients' treatment. Neuroradiology 2006;48:787-94 CrossRef Medline

7. Delgado Almandoz JE, Crandall BM, Fease JL, et al. Diagnostic yield of catheter angiography in patients with subarachnoid hemorrhage and negative initial noninvasive neurovascular examinations. AJNR Am J Neuroradiol 2013;34:833-39 CrossRef Medline

8. Schievink WI, Wijdicks EF. Pretruncal subarachnoid hemorrhage: an anatomically correct description of the perimesencephalic subarachnoid hemorrhage. Stroke 1997;28:2572 Medline

9. Cruz JP, Sarma D, Noel de Tilly L. Perimesencephalic subarachnoid hemorrhage: when to stop imaging? Emerg Radiol 2011;18:197-202 CrossRef Medline

10. Fox AJ, Symons SP, Aviv RI. CT angiography is state-of-the-art first vascular imaging for subarachnoid hemorrhage. AJNR Am J Neuroradiol 2008;29:e41-42; author reply e46-47 CrossRef Medline

11. Prestigiacomo CJ, Sabit A, He W, et al. Three dimensional CT angiography versus digital subtraction angiography in the detection of intracranial aneurysms in subarachnoid hemorrhage. J Neurointerv Surg 2010;2:385-89 CrossRef Medline

12. Kershenovich A, Rappaport ZH, Maimon S. Brain computed tomography angiographic scans as the sole diagnostic examination for excluding aneurysms in patients with perimesencephalic subarachnoid hemorrhage. Neurosurgery 2006;59:798-801; discussion 801-02 CrossRef Medline

13. Kelliny M, Maeder P, Binaghi S, et al. Cerebral aneurysm exclusion by $\mathrm{CT}$ angiography based on subarachnoid hemorrhage pattern: a retrospective study. BMC Neurol 2011;11:8 CrossRef Medline

14. Bradac GB, Bergui M, Ferrio MF, et al. False-negative angiograms in subarachnoid haemorrhage due to intracranial aneurysms. Neuroradiology 1997;39:772-76 CrossRef Medline

15. Urbach $\mathrm{H}$, Zentner $J$, Solymosi $\mathrm{L}$. The need for repeat angiography in subarachnoid haemorrhage. Neuroradiology 1998;40:6-10 CrossRef Medline

16. Luo Z, Wang D, Sun X, et al. Comparison of the accuracy of subtraction CT angiography performed on 320-detector row volume CT with conventional CT angiography for diagnosis of intracranial aneurysms. Eur J Radiol 2012;81:118-22 CrossRef Medline

17. Yeung R, Ahmad T, Aviv RI, et al. Comparison of CTA to DSA in determining the etiology of spontaneous ICH. Can J Neurol Sci 2009; 36:176-80 CrossRef Medline

18. Forster DM, Steiner LL, Hakanson SS, et al. The value of repeat panangiography in cases of unexplained subarachnoid hemorrhage. J Neurosurg 1978;48:712-16 CrossRef Medline

19. Huttner HB, Hartmann M, Köhrmann M, et al. Repeated digital substraction angiography after perimesencephalic subarachnoid hemorrhage? J Neuroradiol 2006;33:87-89 CrossRef Medline

20. Jung JY, Kim YB, Lee JW, et al. Spontaneous subarachnoid haemorrhage with negative initial angiography: a review of 143 cases. J Clin Neurosci 2006;13:1011-17 CrossRef Medline

21. Nishioka H, Torner JC, Graf CJ, et al. Cooperative study of intracranial aneurysms and subarachnoid hemorrhage: a long-term prognostic study, III: subarachnoid hemorrhage of undetermined etiology. Arch Neurol 1984;41:1147-51 CrossRef Medline

22. Hoh BL, Cheung AC, Rabinov JD, et al. Results of a prospective protocol of computed tomographic angiography in place of catheter angiography as the only diagnostic and pretreatment planning study for cerebral aneurysms by a combined neurovascular team. Neurosurgery 2004;54:1329-40; discussion 1340-42 CrossRef Medline

23. Delgado Almandoz JE, Jagadeesan BD, Refai D, et al. Diagnostic yield of repeat catheter angiography in patients with catheter and computed tomography angiography negative subarachnoid hemorrhage. Neurosurgery 2012;70:1135-42 CrossRef Medline 
24. Topcuoglu MA, Ogilvy CS, Carter BS, et al. Subarachnoid hemorrhage without evident cause on initial angiography studies: diagnostic yield of subsequent angiography and other neuroimaging tests. J Neurosurg 2003;98:1235-40 CrossRef Medline

25. Dalyai R, Chalouhi N, Theofanis T, et al. Subarachnoid hemorrhage with negative initial catheter angiography: a review of 254 cases evaluating patient clinical outcome and efficacy of short- and longterm repeat angiography. Neurosurgery 2013;72:646-52; discussion 651-52 CrossRef Medline

26. Ringelstein A, Mueller $\mathrm{O}$, Mönninghoff $\mathrm{C}$, et al. 3D rotational angiography after non-traumatic SAH. Rofo 2014;186:675-79 CrossRef Medline

27. van Rooij WJ, Peluso JP, Sluzewski M, et al. Additional value of 3D rotational angiography in angiographically negative aneurysmal subarachnoid hemorrhage: how negative is negative? AJNR Am J Neuroradiol 2008;29:962-66 CrossRef Medline

28. Fisher CM, Kistler JP, Davis JM. Relation of cerebral vasospasm to subarachnoid hemorrhage visualized by computerized tomographic scanning. Neurosurgery 1980;6:1-9 CrossRef Medline

29. Jagadeesan BD, Delgado Almandoz JE, Moran CJ, et al. Accuracy of susceptibility-weighted imaging for the detection of arteriovenous shunting in vascular malformations of the brain. Stroke 2011;42: 87-92 CrossRef Medline

30. Zaharchuk G, Bammer R, Straka M, et al. Arterial spin-label imaging in patients with normal bolus perfusion-weighted MR imaging findings: pilot identification of the borderzone sign. Radiology 2009;252:797-807 CrossRef Medline

31. van Gijn J, van Dongen KJ, Vermeulen M, et al. Perimesencephalic hemorrhage: a nonaneurysmal and benign form of subarachnoid hemorrhage. Neurology 1985;35:493-97 CrossRef Medline

32. Salvarani C, Brown RD Jr, Calamia KT, et al. Primary central nervous system vasculitis: analysis of 101 patients. Ann Neurol 2007;62: 442-51 CrossRef Medline

33. Singhal AB, Hajj-Ali RA, Topcuoglu MA, et al. Reversible cerebral vasoconstriction syndromes: analysis of 139 cases. Arch Neurol 2011;68:1005-12 CrossRef Medline

34. Wallace AN, Dines JN, Zipfel GJ, et al. Yield of catheter angiography after computed tomography negative, lumbar puncture positive subarachnoid hemorrhage [corrected]. Stroke 2013;44:1729-31 CrossRef Medline

35. Flint AC, Roebken A, Singh V. Primary intraventricular hemorrhage: yield of diagnostic angiography and clinical outcome. Neurocrit Care 2008;8:330-36 CrossRef Medline

36. Maslehaty HH, Barth HH, Petridis AKA, et al. Special features of subarachnoid hemorrhage of unknown origin: a review of a series of 179 cases. Neurol Res 2012;34:91-97 CrossRef Medline

37. van Gijn J, Rinkel GJ. Subarachnoid haemorrhage: diagnosis, causes and management. Brain 2001;124:249-78 CrossRef Medline

38. Yaghi S, Oomman S, Keyrouz SG. Non-aneurysmal perimesencephalic subarachnoid hemorrhage caused by a cavernous angioma. Neurocrit Care 2011;14:84-85 CrossRef Medline 